\title{
The development of an innovative mentorship experience for an online RN-to-BSN program
}

\author{
Melissa A. Wholeben, Gloria McKee, Audrey Tolouian, Diane Rankin \\ School of Nursing, The University of Texas at El Paso, United States
}

Received: September 26, 2020

Accepted: November 17, 2020

Online Published: November 24, 2020

DOI: $10.5430 /$ jnep.v11n3p57

URL: https://doi.org/10.5430/jnep.v11n3p57

\begin{abstract}
The Institute of Medicine, Carnegie Foundation and the American Association of Colleges of Nursing (AACN) initially accelerated the movement to increase the number of Baccalaureate (BSN) prepared nurses in the workforce. Research demonstrated lower mortality rates, fewer medication errors and positive outcomes linked to nurses prepared at the BSN and higher levels. The purpose of this article is to describe the steps utilized in the development of an innovative mentorship project that provides mentored clinical practice experiences to students enrolled in an RN-to-BSN program delivered 100\% online. This mentorship project was developed with two main aims in mind: 1) To develop two quality clinical practice mentorship experiences for online RN-to-BSN students and 2) To provide a process for the implementation and evaluation of the clinical practice mentorship experiences.
\end{abstract}

Key Words: RN-to-BSN program, Mentorship experience, Online format, Leadership, Community

\section{INTRODUCTION}

The Institute of Medicine, ${ }^{[1]}$ Carnegie Foundation ${ }^{[2]}$ and the American Association of Colleges of Nursing (AACN) initially accelerated the movement to increase the number of Baccalaureate (BSN) prepared nurses in the workforce. Re$\operatorname{search}^{[3,4]}$ demonstrated lower mortality rates, fewer medication errors and positive outcomes linked to nurses prepared at the BSN and higher levels. Employers also demonstrated a strong preference for nurses educated at the BSN level. ${ }^{[3]}$ With these findings, national leaders representing both community college and university-based registered nursing (RN) programs developed the "Joint Statement on Academic Progression for Nursing Students and Graduates". [5] This led to a dramatic increase in $\mathrm{RN}$-to-BSN programs across the country, with over $90 \%$ of them delivered completely online.

Since nursing is a practice discipline, RN-to-BSN programs that are $100 \%$ online, must also provide quality clinical learning opportunities and interprofessional experiences to students while maintaining the same academic rigor as face-toface programs. This has posed a challenge to nursing programs, since online RN-to-BSN programs typically include students located all over the U.S. and other countries. Location of clinical sites, supervision of clinical experiences, and evaluation of clinical outcomes from a distance has proven to be more challenging for the online nursing student.

The purpose of this article is to describe the steps utilized in the development of an innovative mentorship project that provides mentored clinical practice experiences to students enrolled in an RN-to-BSN program delivered $100 \%$ online. This mentorship project was developed with two main aims in mind: 1) To develop two quality clinical practice mentorship experiences for online RN-to-BSN students and 2) To States.

*Correspondence: Melissa A. Wholeben; Email: mwholeben@utep.edu; Address: School of Nursing, The University of Texas at El Paso, United 
provide a process for the implementation and evaluation of the clinical practice mentorship experiences.

\section{REVIEW OF THE LITERATURE}

The BSN Essentials, ${ }^{[6]}$ state that all BSN nursing students, regardless of delivery or track, must complete direct care clinical training experiences as part of their program to acquire the degree. The AACN task force delineated the specific clinical training experiences that transitioned a nursing student's role from the Associate Degree or diploma to the BSN level of proficiency. ${ }^{[3]}$ The task force emphasized that practice experiences needed to assure that students attain endof-program competencies delineated in the BSN Essentials. Practice experiences in the RN-to-BSN program involve a variety of activities that include direct care and indirect care experiences that impact health outcomes. BSN programs are expected to provide rich and varied opportunities designed to assist graduates to achieve The Essentials of Baccalaureate Education for Professional Nursing Practice (BSN Essentials). ${ }^{[6]}$

In their 2019 Vision Statement, AACN also supported increased collaboration between education and practice and encouraged all schools of nursing to adopt the AACN \& AONE (American Organization of Nurse Executives) principles for academic practice partnerships. ${ }^{[7]}$ This included identification and preparation of preceptors and mentors for students and new graduates. The process utilized to establish partnerships, mentorships and practice agreements is described in detail in the 'development of the mentorship program' section.

RN-to-BSN educational programs build upon foundational skills obtained in an associate degree. Associate degree and diploma programs cover the provider of care role of the registered nurse very well. However, Baccalaureate programs allow additional time for professional identity formation and include new or additional content in liberal arts, evidencebased practice, organizational leadership, interprofessional collaboration, healthcare policy and finance, and community/population health. ${ }^{[8]}$

The joint task force of AACN explored and identified success strategies for developing academic practice partnerships ${ }^{[9]}$ to provide clinical practice experiences to RN-to-BSN students. The task force published guiding principles that emphasized the need for collaboration and formal relationships at the senior leadership level. ${ }^{[10]}$ According to the principles, relationships must be mutually beneficial and founded in respect, trust, engagement and information sharing. Successful partnerships can result in improved patient outcomes, promote joint appointments, increase faculty practice opportunities, develop new models of clinical education, encourage nursebased research, support nurse residency programs, and increase the numbers of BSN-prepared nurses. ${ }^{[9,11,12]}$

One example of the successful implementation of an academic practice partnership between a School of Nursing and a University Medical Center was described in a pilot cohort program implemented between Vanderbilt University Medical Center (VUMC) and Belmont University School of Nursing (SON). ${ }^{[13]}$ The rationale for VUMC implementing this pilot program was to support their mission as a magnethospital to reach their goal that $80 \%$ of their nursing staff have a BSN degree by the year 2020. The VUMC wanted to minimize the barrier for their employees to receive higher education and maximize utilization of the employee tuition benefits that were available to all employees. The SON goal in this pilot project was to increase the number of $\mathrm{RN}$-toBSN graduates and to collect feedback from RN students throughout the program, which proved to be a win-win for collaboration between the VUMC and the SON. There were nine out of twelve (75\%) RN-to-BSN students participating in the pilot online cohort program who progressed to graduation within four years of starting the program. Their success increased the number of BSN-prepared nurses employed by the VUMC and increased the candidate pool for the VUMC leadership opportunities. ${ }^{[13]}$

Academic Practice partnerships such as the one described in the pilot cohort program between Belmont University School of Nursing and VUMC exemplify the successful collaboration between Schools of Nursing and healthcare facilities in providing clinical practice experiences for online RN-to-BSN students. However, a challenge is encountered for Schools of Nursing which deliver RN-to-BSN programs that are delivered $100 \%$ online and enroll students who live in multiple states throughout the U.S. This challenge occurs when a School of Nursing is not located in the same geographical location as the healthcare facility where their online students live. Students enrolled in an RN-to-BSN program delivered $100 \%$ online typically live in different states throughout the U.S. As a result, it becomes very difficult for collaboration and formal relationships to be formed at the senior leadership level between the Schools of Nursing and multiple healthcare facilities not locally based.

Other obstacles encountered when locating clinical practice sites for online RN-to-BSN students include the acquisition of clinical affiliation agreements required by the School of Nursing and the different healthcare facilities. Affiliation agreements between Schools of Nursing and healthcare facilities typically involve a long process of legal review and approval. This makes the establishment of affiliation agree- 
ments with healthcare facilitates for each student enrolled in an online RN-to-BSN program very difficult to accomplish. In addition, there are obstacles posed by the different regulations required at each healthcare facility for allowing students to enter their facility. This includes differing regulations for health and immunization records, proof of CPR certification, as well as individualized orientations and training required by the nursing education department at the healthcare facility.

\section{DEVELOPMENT OF MENTORSHIP EXPERI- ENCES}

At the initiation of this project, the first aim was to develop direct care mentorship experiences to build upon the registered nurse (RN) experience that would integrate BSN level nursing concepts. The mentorship clinical experiences developed for the RN-to-BSN nursing program were based on guidelines published in the AACN Task Force Recommendations in their 2019 Vision Statement. ${ }^{[3,4]}$ These experiences incorporate both direct and indirect nursing care concepts. Direct nursing care concepts include providing nursing care to patients and collaborating with other healthcare providers to achieve health goals and outcomes. Indirect nursing care concepts include activities such as reviewing best practices, engaging in reflection activities, and completing environmental assessments.

It was essential to include mentorship components that required the students to engage in the skills of both direct and indirect care, interprofessional collaboration, evidence-based practice, and leadership. The RN-to-BSN program consists of five nursing courses of which the final two courses are designed as capstone mentorship courses. The program continues to require students to enhance these skills through completion of their capstone projects under the careful guidance of their mentors and course faculty. Activities include conducting multi-disciplinary interviews that expose the student to interprofessional communication, researching databases and policies, presenting findings to administration and targeted patient populations, and completing reflection journals. The mentorship project is continuously reviewed to ensure that the experiential learning components are aligned to both credentialing essentials (BSN Essentials and Texas Differentiated Essential Competencies) and course and program outcomes (Quality and Safety Education for Nurses, Course Objectives, and RN-to-BSN Program Learning Outcomes).

\subsection{Healthcare delivery learning environment}

When the mentorship project was first implemented during the spring semester of 2019, the RN-to-BSN faculty thought it was important for the students to demonstrate BSN concepts in a leadership project entitled "Develop a Manage-

Published by Sciedu Press ment Proposal to Address a Quality Care or Patient Safety Issue" and a community project entitled "Implementation of a Community Health and Population-Focused Health Promotion Resource Activity \& Community-Based Activity \& Evidence-Based Protocol for Patient Resources". The leadership project requires students to actively engage in a quality improvement initiative based on an identified patient safety concern. The community project entails students assessing their communities and finding resources for the patient populations they serve, and sharing that information with staff members, patients, and families. Students learn how gain new perspectives on improving quality of care and experience what it is like to truly make a difference and become agents of change. During these mentorship projects, students document their mentorship hours, as well as other activities associated with those hours, utilizing a computerized program. This program archives formative and summative evaluations completed by the mentor of the student's progress, along with evaluations of the mentor and facility completed by the student at the end of each course.

The mentorship experience projects were developed based on the premise that the students are employed as registered nurses who are invested in their organizations. Faculty structure activities to help the students develop skills specific to their specialty that will enable them to grow in their profession. Students are encouraged to do their capstone projects within the units or facilities in which they work. At the end of the two capstone courses, a total of 100 hours of mentorship, which include a minimum of 15 hours working directly with their mentors, are to be completed.

Elements of the current mentorship experience projects have evolved based on feedback provided by previous RN-to-BSN students in which they expressed apprehension and uncertainty about interprofessional communication. Students are directed to reach out to colleagues from other disciplines within their institutions and interview them. The intent is to help the students refine their interpersonal communication skills and build relationships with other disciplines within their working environments. Mentors guide their students through this process by sharing their own strategies for facilitating effective communication with other members of the healthcare team.

\subsection{Leadership course mentorship}

The leadership course mentorship allows students to delve into in-house quality management. This course focuses on the knowledge and skills needed to be a nursing leader who can function effectively as a contributing member of the interprofessional team. This project highlights the development of leadership skills and management techniques needed to 
coordinate the provision of safe, quality patient-centered care. Emphasis is on professional behaviors, communication that supports information exchange, collaboration and conflict mediation, ethical comportment and the establishment and provision of evidence-based practice.

The students, guided by their mentors, identify a problem that exists at their facility. It can be for a specific patient population, an in-house policy, or a system that is not working properly. Through a series of pre-established interview question prompts, the students help "solve" the problem. Through interviews and quality initiative (QI) processes, the students identify factors that can influence the identified issue. The student gathers input from interprofessional team members and gains perspective from other angles. This allows the students to interact and observe other disciplines while gathering information needed for their final QI project. Once there is a viable solution to the identified problem, students present their ideas to stakeholders.

An example of a project in this course is as follows: Student A works at a local healthcare facility in the Emergency Department and noticed that there has been an increase in falls following narcotic administration. The student meets with a member of Quality Improvement to discuss the concern of falls and to review current policies in the department, along with the facility's mission and vision, chain of command, and communication structure. The student then researches best practices to find solutions to decrease the incidence of falls. They then present their findings to administration including a Root Cause Analysis and a possible solution. In addition, a policy draft regarding falls and an implementation plan of the proposed solution is presented.

\subsection{Community course mentorship}

The community course mentorship augments the introduction of students to nursing care of individuals, families, groups, communities, and populations. Students explore principles and practices of community health, as well as examining factors that influence the health of populations, and the use of evidence-based practices in the delivery of spiritually and culturally appropriate health promotion and disease prevention interventions. The nurse's role in this project is to create pathways of access to care in the community as a whole.

The student and mentor will first identify a patient population served by their facility. This can be a broad range of groups, so the students will narrow down to a specific aggregate population. The students then complete a windshield survey and an environmental survey of the area surrounding the place where they work. This will help the student ascertain the options available for outpatient care for the identified popu- lation. The students then interview an employee from two identified outpatient care organizations in order to discover the resources and services that are available for their aggregate population. The student develops and creates handouts or other materials for patients prior to discharge. Patients can take this material home to review when needed.

An example of this project is as follows: Student B works in a diabetes clinic. This student has observed patients do not utilize resources outside the clinic. The student conducts a review of the facility (Diabetes clinic) regarding its status as a FQHC/CHC/RHC (Federally Qualified Healthcare/Community Healthcare/Rural Healthcare) in addition to resources available within the clinic. The student then goes out into the community to research potential resources for their population (i.e.: health department, local support groups, etc.). The student then compiles the resource information into a teaching presentation and creates an educational resource handout for the patient and their family.

\section{IMPLEMENTATION OF THE MENTORSHIP PROJECT}

The second aim was creating an internal process that the School of Nursing would use to locate appropriate clinical sites for students, develop clinical practice agreements, locating appropriate mentors and evaluation of student learning outcomes. During the first course of the program, students submit a document that identifies their place of employment and the unit where they work. Once these locations are identified, the director of the program determines if there is an affiliation in place between the School of Nursing and the healthcare facility. As the students work in different specialties throughout the United States, these locations consist of hospitals, clinicals, schools, and home health agencies. The students are asked to provide the name of a potential mentor who possess the qualifications as mandated by Board of Nursing (BON) guidelines. These mentors are vetted based on the following criteria: 1) BON licensure, 2) highest degree earned and 3) willingness to be a mentor for the student during their two practicum courses. As the goal of the mentorship is for students to complete their project in the facility they are currently employed, it is emphasized that the mentorship activities are separate from work hours and duties. During the practicum experience, course faculty meet with the students and mentors to ensure that objectives are being met and answer any questions regarding processes and evaluations.

\subsection{Challenges}

Currently, the RN-to-BSN program courses are $100 \%$ online. As a result, there are inherent challenges related to ensuring 
students can complete their mentorships and successfully achieve course and program outcomes. As many students reside in different states within the United States and overseas with the United States military, it is imperative that the faculty consider issues related to remote learning in order to create an environment of student success.

A challenge often encountered includes securing new affiliation agreements with the vast array of workplaces of remote students as enrollment is open to students throughout the United States working in numerous health care organizations. Other challenges include facilitating mentorships for students that are not currently working as a nurse, students transferring to another facility during the mentorship, and students unable to find a nurse mentor at their facility. These challenges require a thinking outside the box approach to secure strong mentorships. One solution involves students exploring possible mentorship locations within their current communities, such as local clinics and schools. Once an affiliation site is determined and approved, facility administrators sign the agreement. The student then submits the contract to the $\mathrm{RN}$-to-BSN program director. If the student is unable to find a nurse mentor at this facility, the RN-to-BSN faculty assists the student to find a mentor.

In some cases, a facility is not available for the student to complete their mentorship. In these instances, the students complete a virtual mentorship with a local hospital, and complete their projects utilizing an online communication application such as Zoom or Skype. These students still complete all the components of the project using virtual face to face platforms. This includes mentor meetings every week, interviews, and their final presentations to administration, stakeholders, patients, and families.

\subsection{Program outcomes}

Students and Mentors complete evaluations at strategic points during the courses. At the midpoint (formative) of the courses, mentors evaluate the students regarding program outcomes based on BSN essentials and Nursing Program Outcomes. This evaluation is also completed at the conclusion (summative) of each of the courses. The formative and summative evaluations include eleven nursing program outcomes. These outcomes are patient-centered care, teamwork and collaboration, evidence-based practice, quality improvement, safety, informatics, professionalism, leadership, communication, systems-based practice, and health promotion and education. The mentor will evaluate the students on a 4-point Likert scale. For students to pass the mentorship experience, they must receive a 3 or higher on all eleven nursing program outcomes by the summative evaluation in each course. Mentors are able to provide feedback on the students' progress throughout the course. In addition, the student completes a self-evaluation of their teaching presentation and their experience with the mentor and the facility. The evaluation of each mentor and facility is reviewed by the course faculty to determine if the facility and mentor will be a good fit for future nursing students.

In past evaluations, students have reported an improvement in the ability to organize, prioritize, manage, lead and communicate, in both oral and written formats. Comments have included, "I feel more confident in my abilities to provide leadership and manage the care of my patients", and "I never realized how important evidence-based practice (best practice) is to my patient practice". Another student expressed that "Community health projects really emphasized the importance of teamwork and collaboration".

Previous student feedback regarding mentors has been positive. Students have reported "My mentor provided me with a lot of positive feedback ... provided recommendations for conducting research". Other students stated, "My mentor was able to give me insight to a lot of policies and ways of doing things that I was also reading about during the course".

Additionally, when students have described how the mentor facilitated their learning in the capstone courses, comments have reflected the favorable impact the mentors had on their learning experiences. One student commented, "My mentor reinforced the importance of communication and helped me understand the difference in being a nurse and being a BSN nurse". Another student expressed that "My mentor helped me focus on every area of my QI project, such as budget, supplies, knowledge, students and parents."

At the end of each capstone course, students' complete self-evaluations related to their presentations. The capstone project for each course includes a Project Synopsis, where the student highlights the project, provides participant feedback, and self-evaluates the presentation. The final self-evaluation piece ties everything together for the student and provides them with insight on how to approach future professional endeavors.

\section{RECOMMENDATIONS FOR THE FUTURE}

As the mentorship practicum continues, faculty and administration plan to build on the feedback provided by faculty, mentors, and students who have completed these capstone courses, and to put elements in place that further support program success. The first step is to build a resource pool of RNs willing to serve as virtual mentors for students in facilities where affiliation agreements are in place. This will facilitate mentorships for students not currently working as nurses and for students unable to use their workplace for mentorship 
experiences. There is a plan to incorporate additional media applications to assist students with their capstone project presentations for virtual mentorships.

Work will be done to expand options for students to build virtual leadership skills and to forge community connections through programs like telehealth. To evaluate long-term impact of the capstone mentorships, students who have graduated from the program will be surveyed six months after completing their degree to determine if changes have occurred in the graduate's career trajectory. Questions to be answered include "Have new opportunities arisen for the graduate as a result of the relationships built during the capstone mentorships? Has the graduate assumed new leadership positions?"

\section{Conclusion}

It is important that nursing curricula build mentorship opportunities for RN-to-BSN students that both expand their previous knowledge and build upon their nursing experiences. Continuous assessment of the processes that drive the RN-toBSN mentorships will help faculty maximize preparation of RN-to-BSN graduates to be leaders within their workplaces. The nurturing guidance provided by nurse mentors will lay the foundation for RN-to-BSN graduates to foster the interprofessional collaboration needed to ensure patient care is of the highest caliber and a team approach.

\section{CONFlicts OF InTEREST Disclosure}

The authors declare that there is no conflict of interest.

\section{REFERENCES}

[1] Institute of Medicine. The future of nursing: Leading change, advancing health. Washington, DC: National Academies Press; 2011.

[2] Carnegie Foundation for the Advancement of Teaching. 2009. Available from: https://www. carnegiefoundation.org/resourc es/publications

[3] American Association of Colleges of Nursing. (Oct 2012). White paper: Expectations for practice experiences in the $\mathrm{RN}$ to baccalaureate curriculum. Washington, DC: Author. Available from: https://www . aacnnursing.org/Portals/42/News/Wh ite-Papers/RNBSN-Expectations-White-Paper.pdf

[4] American Association of Colleges of Nursing. (Oct 2017) White paper: Expectations for practice experiences in the RN to baccalaureate curriculum. Washington, DC: Author. Available from: https://www. aacnnursing.org/Portals/42/News/Wh ite-Papers/RNBSN-Expectations-InstituteofMedicine (2011) White-Paper.pdf

[5] The Joint Statement on Academic Progression for Nursing Students and Graduates. American Association of Community Colleges (AACC); Association of Community Colleges Trustees (ACCT); American Association of Colleges of Nursing (AACN);National League for Nursing (NLN); National Organization for Associate Degree Nursing (N-OADN). 2012.

[6] American Association of Colleges of Nursing. The essentials of baccalaureate education for professional nursing practice. Washington, DC: Author. 2008.
[7] American Association of College of Nursing. AACN's Vision for Academic Nursing White Paper. Washington, D.C. Author. 2019. Available from: https://www. aacnnursing.org/News-Infor mation/Positions-White-Papers

[8] Kumm S, Godfrey N, Martin D, et al. Baccalaureate outcomes met by associate degree nursing programs. Nurse Educator. 2014; 39(5): 216 220. PMid:24978014 https://doi.org/10.1097/NNE.000000 0000000060

[9] Beal JA, Breslin E, Auston T. Hallmarks of best practice in academicservice partnerships in nursing: Lessons learned from San Antonio. Journal of Professional Nursing. 2011; 27(6): e90-e95. PMid:22142934 https://doi.org/10.1016/j.profnurs . 201 1.07 .006

[10] American Association of Colleges of Nursing and American Association for Nurse Executives (AACN-AONE). (January 2012). Guiding Principles to Academic-Practice Partnerships.

[11] Beal JA, Alt-White A, Erickson J, et al. Academic practice partnerships: A national dialogue. Journal of Professional Nursing. 2012; 28(6): 327-332. PMid:23158195 https://doi.org/10.1016/j . profnurs.2012.09.001

[12] Stout C, Short N, Aldrich K, et al. Meeting the future of nursing report $^{\mathrm{TM}}$ recommendations: A successful practice-academic partnership. Nursing Economics. 2015; 33: 161-166.

[13] Copenhaver D, Dubree M, Wilson C, et al. Outcomes and Experiences of an RN to BSN Online Cohort: An Academic Practice Partnership. International Journal of Health Sciences Education. 2018. 